\title{
Electrospinning TPU/poly o-phenetidine (POEA) fibers: influence of POEA on fiber morphology
}

\author{
Karina Ferreira Noronha $\mathrm{Cruz}^{1} \cdot$ Edson Cocchieri Botelho ${ }^{2}$. \\ Fernando Henrique Cristovan ${ }^{1} \cdot$ Lilia Müller Guerrini $^{1}$
}

Received: 10 May 2016/Revised: 21 November 2016/Accepted: 26 November 2016/Published online: 16 December 2016

(C) Springer-Verlag Berlin Heidelberg 2016

\begin{abstract}
The synthesis of poly (o-phenetidine) (POEA) was performed via chemical oxidative method and doped with dodecylbenzenesulfonic acid. Electrospun fibers of thermoplastic polyurethane (TPU)/poly $o$-phenetidine (POEA) blends were produced. Parameters such as the distance between collector and needle, as well as the applied voltage and the ratio of POEA content were evaluated. The fiber morphology, chemical structure and thermal analysis of the mats were analyzed. TPU nanofibers showed cylindrical morphology with many beads and the fiber diameter was around $330 \mathrm{~nm}$. With the addition of POEA at a percentage of $30 \mathrm{wt} \%$ it was possible to produce uniform fibers without beads with diameters around $400 \mathrm{~nm}$.
\end{abstract}

Keywords Poly o-phenetidine - Thermoplastic polyurethane · Electrospinning · Polymer conductivity

\section{Introduction}

Poly (o-phenetidine) (POEA) is a conductive polymer and belongs to the family of alkoxy anilines, which differ mainly because of the presence of the ethoxy group $\left(\mathrm{O}-\mathrm{C}_{2} \mathrm{H}_{5}\right)$ on the aniline chain. This substituent results in larger distortions of the polymer chains decreasing conjugation and increasing the flexibility of the chain. Thus, POEA has stronger affinity to organic solvents and improves the polymer's solubility [1].

Karina Ferreira Noronha Cruz guerrini@unifesp.br

1 Instituto de Ciência e Tecnologia, Universidade Federal de São Paulo, Talim 330, Vila Nair, São José dos Campos, SP 12232-280, Brazil

2 Universidade Estadual Paulista Júlio de Mesquita Filho (UNESP), Av. Ariberto Pereira da Cunha 333, Portal das Colinas, Guaratinguetá, SP 12.516-410, Brazil 
The POEA stands out because of its good thermal stability, low cost, solubility in organic solvents and significant electrical conductivity. The increased conductivity of POEA is due to a transition from an emeraldine base to an emeraldine salt. This transition occurs by doping with a functionalized organic acid, such as dodecylbenzenesulfonic acid (DBSA) that along with increasing the electrical conductivity, improves thermal stability of this polymer [2, 3]. However, POEA presents poor mechanical properties, and therefore, requires blending with conventional polymers like thermoplastic polyurethane (TPU) to improve flexibility, for example. TPU is one of the most versatile polymers because it combines the elasticity, typical of vulcanized elastomers, with the processability of thermoplastic polymers and usually maintains good mechanical properties $[4,5]$.

The blends can be processed using different techniques. Among them, electrospinning has been deemed highly promising owing to the ability to control the surface morphology, attain diameters ranging from micro to nanometer, produce a large surface area to volume ratio, flexibility and also permits fine tuning of the porosity. This means that the material can be applied in several areas, such as release of drugs [6], sensors [7-9], tissue engineering [10, 11], applications in aerospace (reinforced composites and electrostatic protection) [12], and in biomaterials (scaffolds) [13].

In reported studies, parameters, such as polymer concentration, surface tension, applied voltage and conductivity are considered to be the key factors that determine diameter distribution and morphology of the fiber [14]. According to Bhardway et al. [15], when the conductivity of the solution is very low, the droplet created by surface tension will be unable to stretch enough to form the nanofiber. Therefore, the insufficient elongation of the jet caused by electric force inhibits the formation of uniform fibers. The electrical conductivity of the solution in general can be increased using a solvent with a high dielectric constant or by adding the salt to the polymer solution [16]. Picciani et al. [17] determined that the presence of the polyaniline in the blends increased the conductivity of the system resulting in increased stretching of the jet and a significant decrease in the presence of beads on nanofibers.

We found few studies addressing the synthesis and doping of POEA. Further, we found no studies that evaluated electrospinning conditions using POEA and TPU for potential application in the biomedical area.

This work aims to evaluate the influence of the POEA on morphology, diameter distribution and thermal degradation of the nanofibers produced via the electrospinning process of TPU/POEA blends. The POEA was obtained via chemical oxidative polymerization and doped with DBSA. The morphology (SEM), chemical structure (FTIR), and thermal degradation of TPU/POEA nanofibers were investigated to determine the most adequate processing conditions with an eye toward potential applications as biomaterials. 


\section{Experimental}

\section{Materials}

Thermoplastic polyurethane (TPU) ether-based was acquired from BASF. Dodecylbenzenesulfonic acid solution $70 \mathrm{wt} \%$ in isopropanol (DBSA) and $o$-phenetidine $(97.7 \%)$ were purchased from Sigma Aldrich. The $o$-phenetidine was purified at low pressure; the temperature of monomer distillation was $110{ }^{\circ} \mathrm{C}$. After distillation, the monomer was kept in an amber container at temperature of $-10{ }^{\circ} \mathrm{C}$. The other reagents used in this study are analytical grade and were used without further purification.

\section{Synthesis of poly(o-phenetidine)}

The poly (o-phenetidine) was chemically synthesized using $0.012 \mathrm{~mol}$ of ammonium persulfate in aqueous $1.0 \mathrm{~mol} \mathrm{~L}{ }^{-1} \mathrm{HCl}$ at $-5{ }^{\circ} \mathrm{C}$, using a method employed elsewhere [18]. The synthesis was conducted in excess of $o$-phenetidine with ratio of the monomer to oxidant of 4:1 during $7 \mathrm{~h}$. After this period, the emeraldine salt (Scheme 1) was filtered and dried at $60{ }^{\circ} \mathrm{C}$ for $24 \mathrm{~h}$. Then, the material was solubilized in $500 \mathrm{~mL}$ of ammonium hydroxide solution $0.1 \mathrm{~mol} / \mathrm{L}$, under constant agitation for $24 \mathrm{~h}$ to carry out the deprotonation of the salt. Then, the emeraldine base was washed with a solution of distilled water and ethyl alcohol 50/50\% (v/v) and dried at $60{ }^{\circ} \mathrm{C}$. The doping of the POEA was performed using dodecylbenzenesulfonic acid (DBSA). The monomer to dopant ratio was (1:2). The doping was conducted under continuous stirring for 7 days, according to the literature [19].

\section{Electrospinning}

Electrospinning solutions of TPU/POEA were prepared using THF. Solution concentrations were fixed at $10 \mathrm{wt} \%$. The proportions of POEA in the solutions ranged from 0, 30, 40 and $50 \mathrm{wt} \%$. The TPU was dissolved in THF under magnetic stirring for $3 \mathrm{~h}$. POEA was previously dispersed in THF using ultrasonic equipment and then poured into a TPU solution and stirred for $4 \mathrm{~h}$.

The electrospinning system is made up of a high voltage power supply (Spellman-model $30 \mathrm{R}$ ), a cylindrical collector (grounded conductor) covered with aluminum foil (substrate) and an infusion pump (KD Scientific-Legado 200) with a glass syringe tipped with a stainless needle. The collector rotated at $(62 \pm 3) \mathrm{rpm}$.



Emta:Giot (s:t)

Scheme 1 Chemical structure of poly (o-phenetidine) 
The stainless steel needle has inner diameter $0.8 \mathrm{~mm}$ and length of $25 \mathrm{~mm}$ and was used in this experiment as the positive electrode (connected to high voltage power supply). The processing time was $30 \mathrm{~min}$ for the blends and $20 \mathrm{~min}$ for TPU. The distances between needle and collector were 10 and $14 \mathrm{~cm}$. The flow rate was set at $0.05 \mathrm{~mL} / \mathrm{min}$. The applied voltages were 10,12 and $15 \mathrm{kV}$.

\section{Characterization of electrospun nanofibers}

The chemical structure of the POEA powder and the TPU/POEA blends were analyzed using attenuated total reflectance (ATR) Fourier transform infrared spectroscopy (FTIR, Shimadzu, model IR Affinity-1 Spectrometer). The spectrums were obtained between 650 and $4000 \mathrm{~cm}^{-1}$, and represent an average of 32 scans with a resolution of $2 \mathrm{~cm}^{-1}$.

The morphology of the nanofibers was evaluated by a scanning electron microscope (SEM, Ametek, FEI Inspect S50). The number-average nanofibers diameter and its distribution were quantified using the Image-Pro program. The calculation of the average diameter was based on 120 measurements.

Thermogravimetric analysis (TGA) and DTG of the TPU/POEA mats were performed using a TG SII SEIKO Nanotechnology EXSTAR, model 6000 from 30 to $800{ }^{\circ} \mathrm{C}$ at a heating rate of $10^{\circ} \mathrm{C} / \mathrm{min}$ under nitrogen.

The melting temperature $\left(T_{\mathrm{m}}\right)$, the melting enthalpy $\left(\Delta H_{\mathrm{m}}\right)$ and the degree of crystallinity $\left(X_{\mathrm{c}}(\%)\right.$ were measured through differential scanning calorimetry (DSC Netzsch F1 Phoenix). Approximately $11 \mathrm{mg}$ were heated from $30{ }^{\circ} \mathrm{C}$ to $250{ }^{\circ} \mathrm{C}$ at a rate of $10^{\circ} \mathrm{C} / \mathrm{min}$. The degree of crystallinity was calculated according to Eq. 1 .

$$
X_{\mathrm{c}}(\%)=\frac{\varnothing \Delta H_{\mathrm{m}}^{\theta}}{\Delta H_{\mathrm{m}}} \times 100
$$

where $\varnothing$ is the weight fraction of POEA in the blend, $\Delta H_{\mathrm{m}}$ is the enthalpy of fusion determined by the DSC, and $\Delta H_{\mathrm{m}}^{\theta}=171.87 \mathrm{~J} / \mathrm{g}$ referring to the melting heat of $100 \%$ crystalline TPU [20].

DC-conductivity measurements of TPU/POEA produced as films by casting were carried out by a standard four probe method using Jandel (RM 3000). The electrical conductivity values were calculated using Eq. 2.

$$
\sigma=\frac{1}{4.2209 \cdot R \cdot l}
$$

where the $\sigma$ is the electrical conductivity $\left(\mathrm{S} \mathrm{cm}^{-1}\right)$ of the sample, $l$ is the sample thickness $(\mathrm{cm})$ and $R$ is the resistivity of the film $(\Omega)$.

\section{Results and discussion}

\section{Effect of applied voltage}

The applied voltage is a parameter crucial to jet control formed between the collector and needle. According to [21-23], the application of an external electrical 
field must be sufficiently high to overcome the surface tension of the solution, and thus induce the formation of the jet and the resulting fibers. The effect of applied voltage on the morphology of the TPU/POEA mats was verified using 10, 12 and $15 \mathrm{kV}$. Figure 1 shows the morphology of the TPU/POEA mats in the proportion $60 / 40 \mathrm{wt} \%$ produced using applied voltage 10, 12 and $15 \mathrm{kV}$. The distance between collector metallic and needle was fixed at $14 \mathrm{~cm}$. The applied voltage did, in fact, generate cylindrical microfibers; however, it provoked a high incidence of beads (defects). Bead formation may occur due to instability in the polymer jet during production of the mat. This instability can be caused by an increase in electrostatic force brought about by increasing the applied voltage. In general, bead formation is attributed to high surface tension in the solution. This suggests that increasing the electrostatic force to promote elongation of the polymer jet without beads can cause jet instability when the electrostatic force is higher than necessary for the surface tension of the system. The electrostatic forces can be changed by both the applied voltage and by adding charge to the solution. [14, 23]. The SEM images indicate that it is necessary to decrease the electrical field (decrease the applied voltage or increase the distance between needle and collector) of the system to eliminate the formation of the beads. When the applied voltage increased from 10 to $12 \mathrm{kV}$ there was a decrease of the amount of the fibers obtained in the collector, due mainly to the increase of the surface area and higher stability in the jet elongation in this condition.

\section{Effect of working distance}

The influence of the distance between collector and needle tip on morphology and diameter distribution can be observed in Fig. 2. Mats of TPU/POEA 70/30 wt\% were produced using applied voltage $15 \mathrm{kV}$ and working distance of 10 and $14 \mathrm{~cm}$. In both cases fibers were produced with cylindrical morphology with few defects. The decrease in the electrical field in conjunction with the increase of distance from 10 to $14 \mathrm{~cm}$ did not significant differences in morphology and diameter distribution for this system. According to Costa [16], the most appropriate distance between collector and needle should be sufficient for the complete evaporation of the solvent, thus ensuring no occurrence of junctions in the nanofibers. A maximum distance should also be established so that the electric field can effectively stabilize the Taylor cone, and thereby promote the uniformity of nanofibers. In this case, the two distances used were sufficient to allow for complete evaporation of the solvent given that there were no junctions in the nanofibers.

\section{Effect of POEA proportions}

Figures 3 and 4 show the morphology and diameter distribution of the electrospun blends of TPU/POEA in ratios 100/0, 70/30, 60/40 and 50/50 wt\% processed at $10 \mathrm{~cm}$ and $15 \mathrm{kV}$. The SEM image (Fig. 3a) shows the morphology obtained for a TPU mat. We observed that the lower dielectric constant of the THF used in the solution does not favor the formation of fibers due to the small electrical field created by the $15 \mathrm{kV}$ and $10 \mathrm{~cm}$, which result in fiber formation with many beads. 
Fig. 1 Influence of applied voltage on TPU/POEA 60/40 wt $\%$, nanofibers morphology, and diameter distribution. The work distance used was of 14 cm: a $10 \mathrm{kV}$, b $12 \mathrm{kV}$ and c $15 \mathrm{kV}$

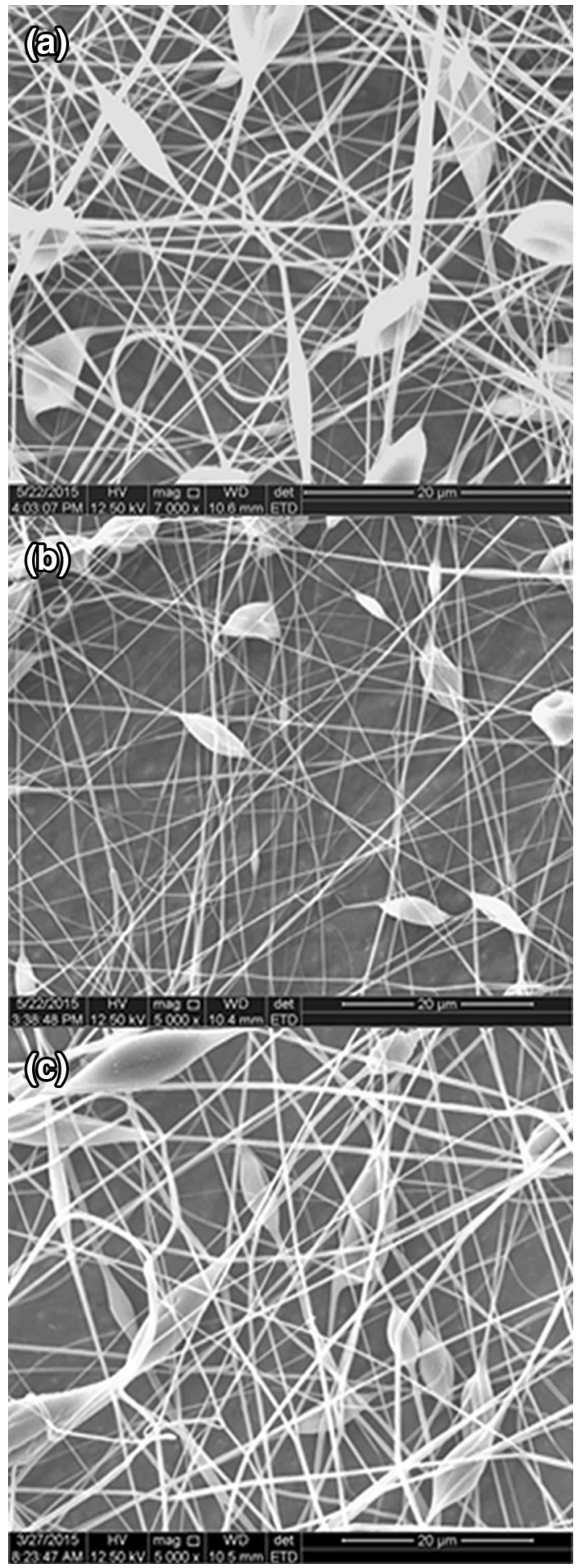



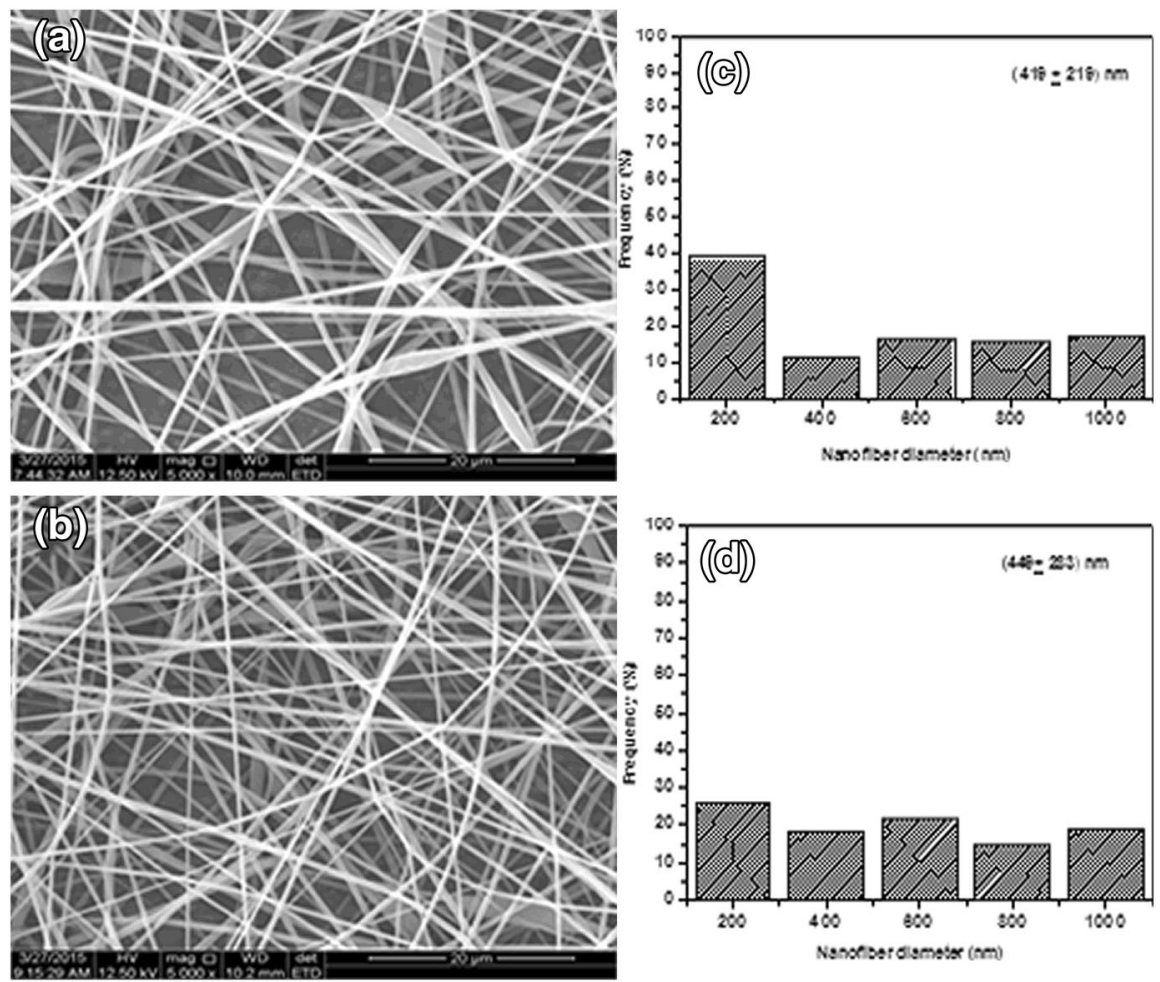

Fig. 2 Morphology and diameter distribution histogram for TPU/POEA 70/30 wt \% nanofibers produced at varying distance between collector and needle: a, c $10 \mathrm{~cm} ; \mathbf{b}, \mathbf{d} 14 \mathrm{~cm}$. The voltage applied was $15 \mathrm{kV}$

According to Shin et al. [24], polymers of low conductivity such as TPU require high electrical fields to induce stable jets. However, the incorporation of POEA in the blend created conditions for TPU/POEA mats with different morphology due to the increased of charge density in the solution, and consequently in the electrical conductivity of the solution. With the addition of 30\% POEA (Figs. 3b, 4b) in the blend, fibers were produced with a mean diameter around $419 \mathrm{~nm}$ and practically without the presence of beads. The increased conductivity of the solution subject to electrical voltage induced a stable jet and formed fibers without beads. However, the addition of $40 \%$ POEA in the solution blend caused a significant increase in the charge density in the solution, and consequently increased the electrostatic forces of the system. This increase of the electrostatic forces allowed elongation of the drops and the jet was formed generating fibers with smaller diameters, but due the instability of the jet, beads were found. According to Fig. 4c, the TPU/POEA mat $60 / 40 \mathrm{wt} \%$ exhibits fibers with smaller diameters $(337 \mathrm{~nm})$ with a high incidence of beads. A similar effect can be observed with the addition of POEA $50 \mathrm{wt} \%$, because the electrostatic force in this case was even greater, generating a polymer jet that was less stable, and consequently a larger number of defects.

The effect of the POEA content on the diameter distribution and defect formation is shown in Table 1. Observe that the distance between collector and needle and the 

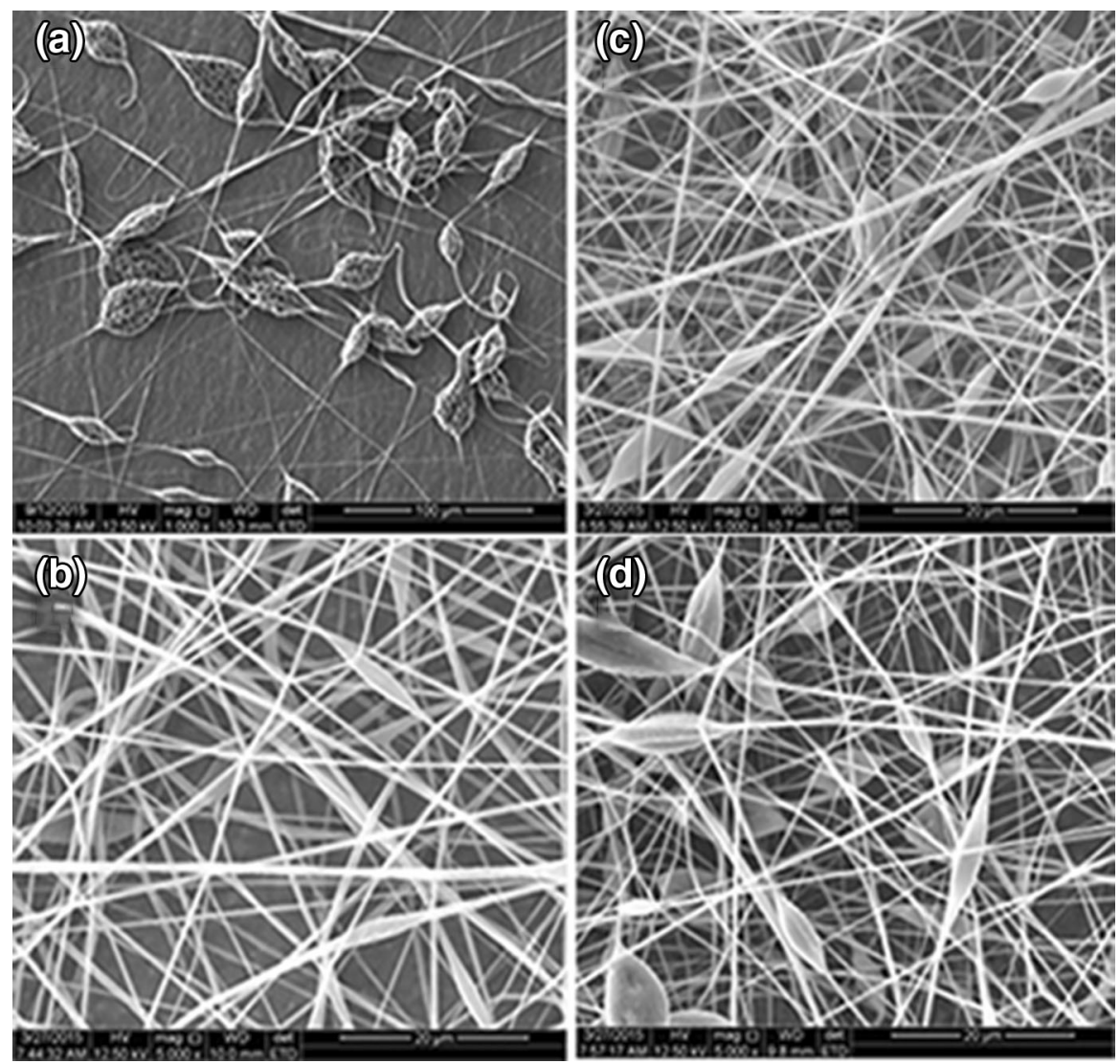

Fig. 3 Effect of POEA proportions on nanofibers morphology: scanning electron micrographs of POEA: a 100/0; b 70/30; c 60/40; and d 50/50 wt \%. The distance between collector and needle was fixed in $10 \mathrm{~cm}$ and applied voltage $15 \mathrm{kV}$

applied voltage were not the main parameters responsible for changes in diameter and bead formation. Rather, the addition of POEA in the solution caused several differences in the morphology obtained. The increase from 30 to $40 \mathrm{wt} \%$ of POEA in the blend, allowed for the formation of fibers with smaller diameters due to increased electrostatic forces. However, the number of beads formed was significantly higher than for the $70 / 30 \mathrm{wt} \%$. TPU/POEA mat. In previous study performed by Cruz et al. [19], the incorporation of POEA in the blend TPU/POEA shows interesting results to be used as scaffolds.

\section{Chemical structure evaluation}

The FTIR spectra of the blends of TPU/POEA and POEA powder are shown in Fig. 5. The successful synthesis and doping of POEA was confirmed mainly by the existence of the bands characteristic of vibration in benzenoid (C-C, $\left.1572 \mathrm{~cm}^{-1}\right)$ and quinoid $\left(\mathrm{C}=\mathrm{C}, 1471 \mathrm{~cm}^{-1}\right)$ rings [25]. The region between 1240 and $1020 \mathrm{~cm}^{-1}$ 

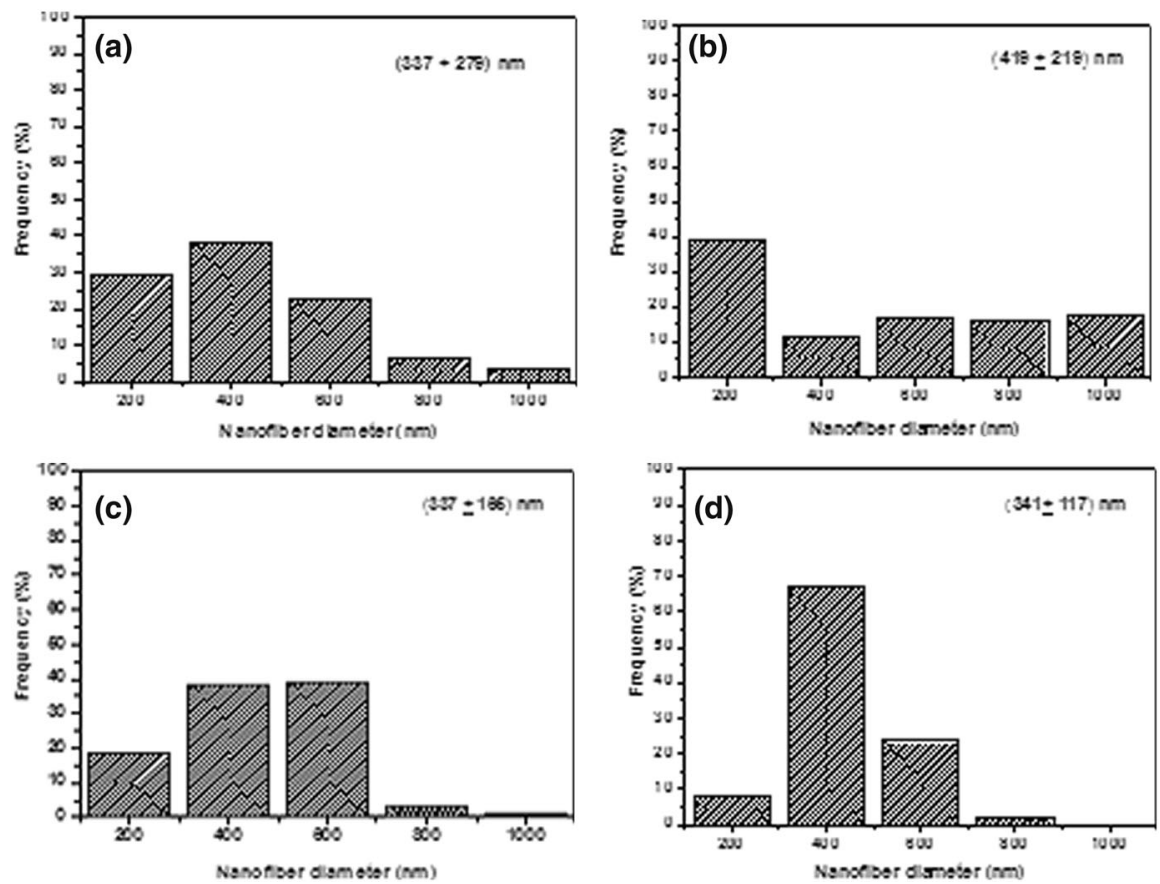

Fig. 4 Effect of POEA proportions in the diameter distribution of the nanofibers: a 100/0; b 70/30; c 60/ 40; d 50/50 wt $\%$. The distance between collector and needle was fixed in $10 \mathrm{~cm}$ and applied voltage $15 \mathrm{kV}$

Table 1 Influence of electrospinning process variables for TPU/POEA nanofibers: (a) diameters distribution and (b) number of defects

\begin{tabular}{lllllc}
\hline $\begin{array}{l}\text { TPU/POEA } \\
\text { wt\% }\end{array}$ & $V(\mathrm{kV})$ & $\begin{array}{l}\text { WD } \\
(\mathrm{cm})\end{array}$ & $\begin{array}{l}\text { Average } \\
\text { diameters }(\mathrm{nm})\end{array}$ & $\begin{array}{l}\text { Standard } \\
\text { deviation }(\mathrm{nm})\end{array}$ & $\begin{array}{l}\text { Number } \\
\text { of beads }\end{array}$ \\
\hline $70 / 30$ & 12 & 14 & 451 & 295 & 0 \\
& 12 & 10 & 441 & 306 & 7 \\
& 15 & 14 & 449 & 283 & 2 \\
$60 / 40$ & 15 & 10 & 419 & 219 & 3 \\
& 10 & 14 & 326 & 191 & 14 \\
& 10 & 10 & 328 & 171 & 16 \\
& 12 & 14 & 304 & 179 & 34 \\
& 12 & 10 & 302 & 182 & 25 \\
$50 / 50$ & 15 & 14 & 317 & 171 & 16 \\
& 15 & 10 & 337 & 165 & 17 \\
& 10 & 10 & 401 & 239 & 14 \\
& 12 & 14 & 335 & 192 & 34 \\
& 12 & 10 & 446 & 224 & 11 \\
& 15 & 14 & 410 & 212 & 20 \\
\hline
\end{tabular}


Fig. 5 FT-IR spectra of POEA powder and TPU/POEA electrospun $(100 / 0,70 / 30,60 / 40$ and $50 / 50 \mathrm{wt} \%$ )

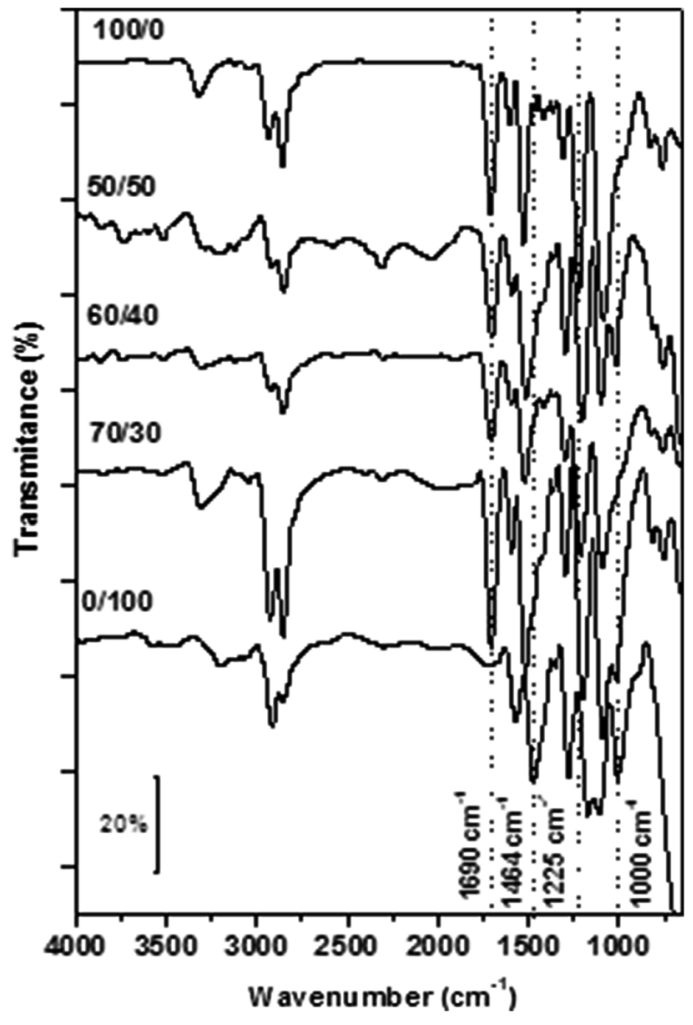

is attributed to symmetric and asymmetric stretching of $(\mathrm{C}-\mathrm{O}-\mathrm{C})$ characteristic of the ethoxy group [26]. The doping is confirmed by bands in the region 1179 and $1005 \mathrm{~cm}^{-1}$ referring to the group $\left(\mathrm{SO}_{3} \mathrm{H}\right)$ present in the DBSA molecules $[16,27,28]$. The TPU nanofibers shows the principal bands at $3320 \mathrm{~cm}^{-1}$ attributed to the $(\mathrm{N}-\mathrm{H})$ stretching mode of the urethane group, $2940 \mathrm{~cm}^{-1}\left(\mathrm{CH}_{2}\right)$, $1750-1650 \mathrm{~cm}^{-1}$ attributed the carbonyl symmetric stretch vibration, and $1120-1000 \mathrm{~cm}^{-1}$ which refers to the ether absorption. In TPU/POEA nanofibers it could be seen that although the mats have been prepared with different concentrations of POEA, the spectra were quite similar to each other and the peaks appear at the same bands. The differences between the three spectra based on the mats are the intensity of some peaks. We observed that the bands at 3320 and $2940 \mathrm{~cm}^{-1}$ demonstrated greater intensity due mainly to the high proportion of TPU in the blend containing $30 \mathrm{wt} \%$ of POEA.

\section{Thermal degradation analysis}

Thermograms of the degradation of TPU/POEA mats with different compositions show weight loss as a function of temperature (TGA) as well as the derivative of weight loss (DTG) in Fig. 6a, b, respectively. The quantitative data are summarized in Table 2. While each of the TPU/POEA blends exhibited initial decomposition 
Fig. 6 Degradations thermograms of POEA powder and TPU/POEA nanofibers
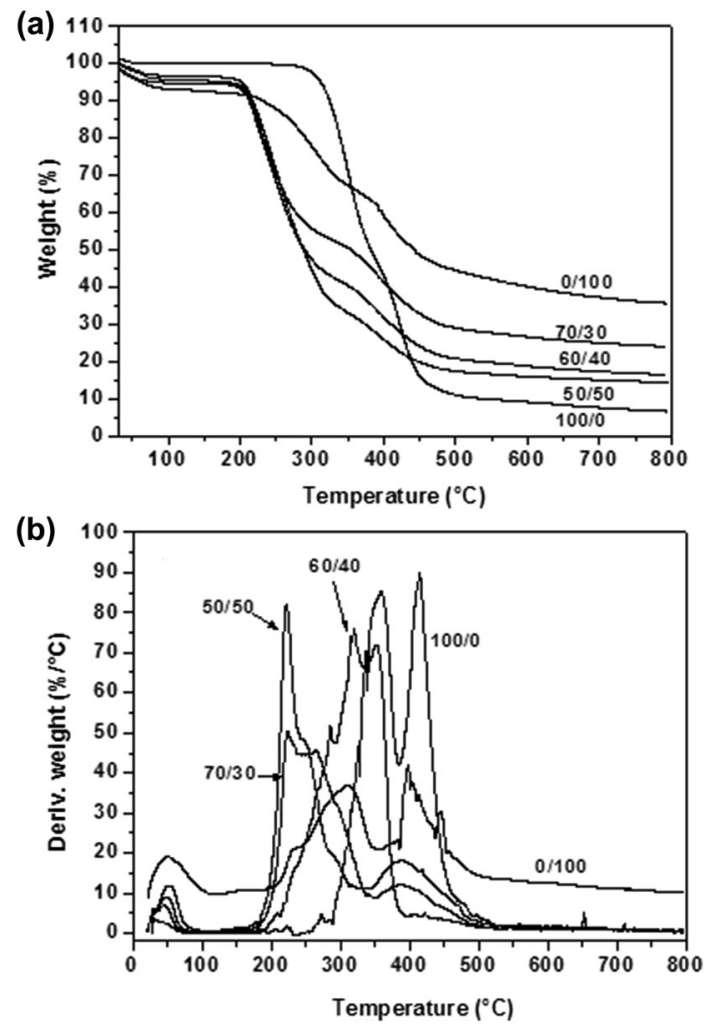

Table 2 TGA data of neat POEA and TPU/POEA nanofibers

\begin{tabular}{lllll}
\hline $\begin{array}{l}\text { Sample } \\
\text { TPU/POEA } \\
(\text { wt } \%)\end{array}$ & $\begin{array}{l}\text { Initial } \\
\text { decomposition } \\
\text { temperature, } T_{\mathrm{i}}\left({ }^{\circ} \mathrm{C}\right)\end{array}$ & $\begin{array}{l}\text { Temperature corresponding } \\
\text { to } 50 \% \text { decomposition }\left({ }^{\circ} \mathrm{C}\right)\end{array}$ & $\begin{array}{l}\text { Maximum } \\
\text { decomposition } \\
\text { temperature }\left({ }^{\circ} \mathrm{C}\right)\end{array}$ & $\begin{array}{l}\text { Residue at } \\
795{ }^{\circ} \mathrm{C} \\
(\%)\end{array}$ \\
\hline $100 / 0$ & 259 & 389 & 371 & 8.6 \\
$70 / 30$ & 117 & 300 & 290 & 14.1 \\
$60 / 40$ & 122 & 300 & 237 & 16.5 \\
$50 / 50$ & 140 & 370 & 238 & 24.0 \\
$0 / 100$ & 112 & 449 & 355 & 35.9 \\
\hline
\end{tabular}

around $120{ }^{\circ} \mathrm{C}$, the onset of the second event changed according POEA content. For the blends containing 30 and $40 \mathrm{wt} \%$ POEA, the weight loss reaches $50 \%$ at $300{ }^{\circ} \mathrm{C}$. However, for the blend with $50 \mathrm{wt} \%$ POEA, the degradation temperature occurs at around $370{ }^{\circ} \mathrm{C}$. According to the DTG, TPU/POEA nanofibers exhibit degradation peaks at similar temperatures, i.e., the increase of POEA in the blend from 30 to 50 wt $\%$ did not significantly affect the weight loss obtained. A major amount of residue was observed in the blend with $50 \mathrm{wt} \%$ POEA, due probably to incomplete decomposition of aromatic rings present in the POEA chains [29]. 
Fig. 7 DSC thermograms of TPU/POEA mats

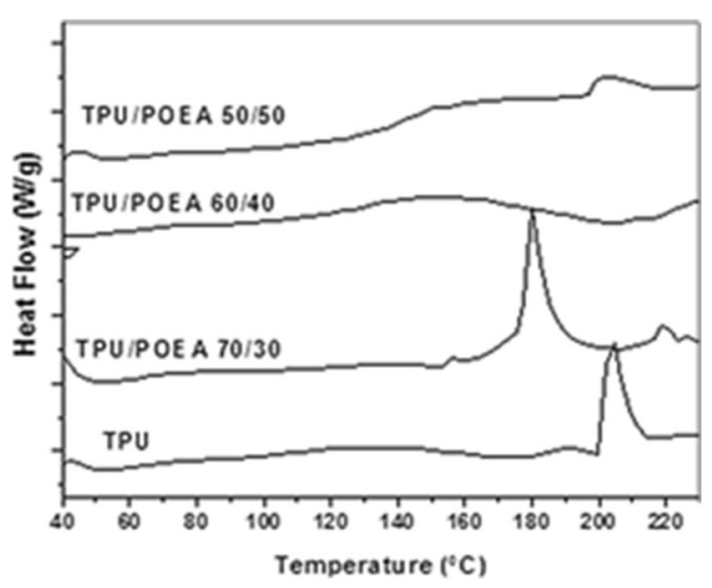

Table 3 Data summarized from DSC of TPU/POEA mats

\begin{tabular}{llll}
\hline Mats of TPU/POEA & $T_{\mathrm{m}}\left({ }^{\circ} \mathrm{C}\right)$ & $\Delta H_{\mathrm{m}}(\mathrm{J} / \mathrm{g})$ & $X_{\mathrm{c}}(\%)$ crystallinity \\
\hline $100 / 0$ & 204 & 19.7 & 9.7 \\
$70 / 30$ & 180 & 29.0 & 23.1 \\
$60 / 40$ & 152 & 34.2 & 37.6 \\
$50 / 50$ & 203 & 5.54 & 5.5 \\
\hline
\end{tabular}

From Fig. 6b, one can observe that the degradation process in all cases is very complex since there are two DTG peaks. Apparently, the presence of TPU reduces the thermal stability of the material.

\section{Thermal behavior analyses}

The DSC heating scan was used to verify the effect of POEA addition on parameters, such as melting temperature $\left(T_{\mathrm{m}}\right)$, fusion enthalpy $\left(\Delta H_{\mathrm{m}}\right)$ and degree of crystallinity $\left(X_{\mathrm{c}} \%\right)$ of TPU/POEA mats. Electrospun TPU/POEA mats in the proportions 100/0, 70/30, 60/40 and 50/50 wt\%, were analyzed and the result is shown in Fig. 7. The data are summarized in Table 3. According Kannan et al. [30], the $T_{\mathrm{m}}$ value of the crystalline component used in the blend is associated with morphology and thermodynamic factors, while the $\%$ crystallinity and enthalpies of fusion are also dependent on the blend composition. The DSC thermograms (Fig. 7) show a $T_{\mathrm{m}}$ for TPU at $204{ }^{\circ} \mathrm{C}$ and similar values have been reported in the literature [19, 31]. This peak can be attributed to the hard segment of TPU. The addition of POEA in the blend decreased the value of $T_{\mathrm{m}}$. For the blends with 30 and $40 \mathrm{wt} \%$ of POEA in the mat, the melting temperature was 180 and $152{ }^{\circ} \mathrm{C}$, respectively, and a similar value of $T_{\mathrm{m}}$ was obtained in the mat with $50 \%$ of POEA. The degree of crystallinity of the TPU was $9.7 \%$ and this value is similar to the degree of crystallinity (8\%) reported by Barick et al. [19]. The degree of crystallinity of the blend with $30 \%$ of POEA was greater than that of the TPU and the melting peak is sharp indicating the presence of organized crystalline structures. Wang et al. [29], produced composites of TPU/PANI by in situ 
polymerization of PANI with different concentrations of anilines $(0,20,30$ and $40 \%)$. They found two melting peaks in the composites and a sharp melting peak in the presence of PANI. They suggested that PANI acts in the TPU polyether chain as a nucleating agent. The blends of POEA with 40 and $50 \mathrm{wt} \%$ (Fig. 7) exhibit broad peaks, and thus a less organized crystalline structure. However, in the blend with $40 \%$ of POEA, the crystallinity is high indicating strong influence of POEA in the process of crystallization of the blend. In the blend with 50\% of POEA, the thermograms show a melting temperature similar to the TPU and low degree of crystallinity since it is practically amorphous. Therefore, the POEA contributes to the formation of a crystalline structure in the blend up to $40 \mathrm{wt} \%$. Above $40 \mathrm{wt} \%$ POEA, the crystallization of TPU is inhibited by POEA and as a result, an amorphous structure is predominant.

\section{Electrical characterization}

The DC-conductivity measurement of the TPU/POEA films prepared by casting was carried using the four probe method. The values of electrical conductivity of the TPU/POEA mats could not be measured because the thickness of the mats was not appropriate to allow a good electrical contact with probe. Thus, we evaluated the electrical conductivity of the blends in film form. The values obtained were $1.4 \times 10^{-5}, 1.1 \times 10^{-4}$ and $1.0 \times 10^{-3} \mathrm{~S} / \mathrm{cm}$ for blends with 30,40 and $50(\mathrm{wt} \%)$ of POEA, respectively. The larger amount of POEA in the blend significantly increased the electrical conductivity values which corroborate results obtained by Vicentini et al. [32]. Norrisa et al. [33] evaluated the DC electrical conductivity of the PANI/polyethylene oxide (PEO) blends prepared in film form (casting) and mats (electrospinning). The authors showed that the values of electrical conductivity increase with greater concentration of PANI in the PEO/PANI blends independent of the method. However, the electrical conductivity values obtained in the mat form is significantly less than films due to reduced surface area between mat and probe. In this perspective, the electrical conductivity values of TPU/POEA mats can be relatively less than films obtained by casting.

\section{Conclusions}

The synthesis and doping of POEA/DBSA was conducted successfully. The electrospun POEA nanofibers were produced using different proportions of POEA solution. The incorporation of the POEA in the blend increased the stability of the jet, and consequently the fibers were formed without beads. The distance between needle and collector did not exhibit significant influence in this work. Using solutions of POEA with 40 and $50 \mathrm{wt} \%$ produced fibers with beads due to the effect of the increase of ions density in the solution and resulting increase in the electric field. In the blend with POEA $30 \mathrm{wt} \%$, produced uniform nanofibers with cylindrical morphology without beads giving this material the potential to be used in applications as a biomaterial. 
Acknowledgements The authors would like to thank CNPq and FAPESP for the financial support 2011/21694-5.

\section{References}

1. Li XG, Duan W, Huang MR, Yang YL, Zhao DY (2003) Preparation and solubility of a partial ladder copolymer from $p$-phenylenediamine and $o$-phenetidine. Polymer 44:6273-6285. doi:10.1016/ S0032-3861(03)00677-3

2. Wang TL, Yang CH, Shieh YT, Yeh AC (2009) Synthesis and properties of conducting organic/ inorganic polyurethane hybrids. Eur Polym J 45:387-397. doi:10.1016/j.eurpolymj.2008.11.020

3. Souza FG, Anzai TK, Melo AP, Soares BM, Nele M, Pinto JC (2008) Influence of reaction media on pressure sensitivity of polyanilines doped with DBSA. J Appl Polym Sci 107:2404-2413. doi:10. 1002/app. 27290

4. Chen CH, Kan YT, Mao CF, Liao WT, Hsieh CD (2013) Fabrication and characterization of waterbased polyurethane/polyaniline conducting blend films. Surf Coat Technol 231:71-76. doi:10.1016/j. surfcoat.2012.03056

5. Dogan SK, Reyes EA, Rastogi S, Ozkoc G (2014) Reactive compatibilization of PLA/TPU blends with a diisocyanate. J Appl Polym Sci 131:1-10. doi:10.1002/app.40251

6. Paaver U, Heinamaki J, Laidmae I, Lust A, Kozlava J, Sillaste E, Kirsimae K, Veski P, Kogermann K (2015) Electrospun nanofibers as a potential controlled-release solid dispersion system for poorly water-soluble drugs. Int J Pharm 479:252-260. doi:10.1016/j.ijpharm.2014.12024

7. Patil PT, Rajshri AS, Kondawar SB (2015) Development of electrospun polyaniline/ZnO composite nanofibers for LPG sensing. Procedia Mater. Sci. 10:195-204. doi:10.1016/j.mspro.2015.06041

8. Li P, Zheng X, Zhang Y, Yuan M, Jiang B, Deng S (2015) Humidity sensor based on electrospun (Na $0.5 \mathrm{Bi} 0.5) 0.94 \mathrm{TiO}_{3}-\mathrm{Ba} 0.06 \mathrm{TiO}_{3}$ nanofibers. Ceram Int 41:14251-14257. doi:10.1016/j.ceramint. 2015.07054

9. Brugnollo ED, Paterno LG, Leite LF, Fonseca FJ, Constantino CJL, Antunes AP, Mattoso LHC (2008) Fabrication and characterization of chemical sensors made from nanostructured films of poly (o-ethoxyaniline) prepared with different doping acids. Thin Solid Film 516:3274-3281. doi:10.1016/ j.tsf.2007.08.118

10. Kucinska-Lipka J, Gubanska I, Janik H, Sien Kiewicz M (2015) Fabrication of polyurethane and polyurethane based composite fibres by the electrospinning technique for soft tissue engineering of cardiovascular system. Mater Sci Eng C 46:166-176. doi:10.1016/j.msec.2014.10.027

11. Mi HY, Salick MR, Jing X, Crone WC, Peng XF, Turng LS (2015) Electrospinning of unidirectionally and orthogonally aligned thermoplastic polyurethane nanofibers: fiber orientation and cell migration. J Biomater Mater Res Part A 103:593-603. doi:10.1002/jbm.a.35208

12. Ohlan A, Singh K, Gandhi N, Chandra A, Dhawan SK (2011) Microwave absorption properties of $\mathrm{NiCoFe}_{2} \mathrm{O}_{4}$-graphite embedded poly (o-phenetidine) nanocomposites. AIP Adv 1:032157-1-0321577. doi: $10.1063 / 1.3642603$

13. Piza AM, Constantino CJL, Venancio EC, Mattoso LHC (2003) Interaction mechanism of poly (oethoxyaniline) and collagen blends. Polymer 44:5663-5670. doi:10.1016/S0032-3861(03)00612-8

14. Casasola R, Thomas NL, Trybala A, Georgiadou S (2014) Electrospun poly lactic acid (PLA) fibres: effect of different solvent systems on fibre morphology and diameter. Polymer 55:4728-4737. doi:10. 1016/j.polymer.2014.06032

15. Bhardwaj N, Kundu SC (2010) Electrospinning: a fascinating fiber fabrication technique. Biotechnol Adv 28:325-347. doi:10.1016/j.biotechadv.2010.01.004

16. Costa RGF, Oliveira JE, Paula GF, Picciani PHS, Medeiros ES, Ribeiro C, Mattoso LHC (2012) Eletrofiação de Polímeros em Solução. Parte I: Fundamentação Teórica. Polímeros: Ciência e Tecnologia 22:170-177

17. Picciani PHS, Soares BG, Medeiros ES, Souza FGJ, Wood DF, Orts WJ, Mattoso LHC (2009) Development of conducting polyaniline/poly (lactic acid) nanofibers by electrospinning. J Appl Polym Sci 112:744-753. doi:10.1002/app.29447

18. Mattoso LHC, Manohar SK, Macdiarmid AG, Eptein AJ (1995) Studies on the chemical syntheses and on the characteristics of polyaniline derivatives. J Polym Sci Part A Polym Chem 33:1227-1234. doi:10.1002/pola.1995.080330805 
19. Cruz KFN, Formaggio DMD, Tada DB, Cristovan FH, Guerrini LM (2016) Development of electroactive nanofibers based on thermoplastic polyurethane and poly(o-ethoxyaniline) for biological applications. J Biomed Mater Res Part A. doi:10.1002/jbm.a.35928

20. Barick AK, Tripathy DK (2012) Preparation and characterization of carbon nanofiber reinforced thermoplastic polyurethane nanocomposites. J Appl Polym Sci 124:765-780. doi:10.1002/app.35066

21. Vashisth P, Pruthi PA, Singh RP, Pruthi V (2014) Process optimization for fabrication of gellan based electrospun nanofibers. Carbohydr Polym 109:16-21. doi:10.1016/j.carbpol.2014.03003

22. Okutan N, Terzi P, Altay F (2014) Affecting parameters on electrospinning process and characterization of electrospun gelatin nanofibers. Food Hydrocoll. 39:19-26. doi:10.1016/j.foodhyd.2013.12. 022

23. Li D, Xia Y (2004) Electrospinning of nanofibers: reinventing the wheel? Adv Mater 16:1151-1170. doi:10.1002/adma.200400719

24. Shin YM, Hohman MM, Brenner MP, Rutledge GC (2001) Experimental characterization of electrospinning: the electrically forced jet and instabilities. Polymer 42:09955-09967. doi:10.1016/ S0032-3861(01)00540-7

25. Gribkova OL, Nekrasov AA, Ivanov VF, Kozarenko OA, Posudievsky OY, Vannikov AV, Koshechko VG, Pokhodenko VD (2013) Mechanochemical synthesis of polyaniline in the presence of polymeric sulfonic acids of different structure. Synth Met 180:64-72. doi:10.1016/j.synthmet.2013. 08.004

26. Cossari P, Bavastrello V, Nicolini C (2013) Influence of multi-walled carbon nanotubes concentration on the properties of nanocomposites with poly(o-ethoxyaniline). Synth Met 176:1-10. doi:10. 1016/j.synthmet.2013.08.004

27. Misoon O, Seok K (2012) Effect of dodecyl benzene sulfonic acid on the preparation of polyaniline/ activated carbon composites by in situ emulsion polymerization. Electrochim Acta 59:196-201. doi:10.1016/j.electacta.2011.10058

28. Sattar R, Kausar A, Siddiq M (2015) Thermal, mechanical and electrical studies of novel shape memory polyurethane/polyaniline blends. Chin J Polym Sci 33:1313-1324. doi:10.1007/s10118-0151680-5

29. Wang J, Yang W, Tong P, Lei J (2010) A novel soluble PANI/TPU composite doped with inorganic and organic compound acid. J Appl Polym Sci 115:1886-1893. doi:10.1002/app.31358

30. Kannan M, Bhagawan SS, Thomas S, Joseph K (2013) Thermogravimetric analysis and differential scanning calorimetric studies on nanoclay-filled TPU/PP blends. J Therm Anal Calorim 112:1231-1244. doi:10.1007/s10973-012-2693-8

31. Frick A, Rockman A (2004) Characterization of TPU-elastomers by thermal analysis (DSC). Polym Test 23:413-417. doi:10.1016/j.polymertesting.2003.09.013

32. Vicentini DS, Barra GMO, Bertolino JR, Pires ATN (2007) Polyaniline/thermoplastic polyurethane blends: preparation and evaluation of electrical conductivity. Eur Polym J 43:4565-4572. doi:10. 1016/j.eurpolymj.2007.06046

33. Norrisa ID, Shaker MM, Kob FK, MacDiarmid AG (2000) Electrostatic fabrication of ultrafine conducting fibers: polyaniline/polyethylene oxide blends. Synth Met 114:109-114. doi:10.1016/ S0379-6779(00)00217-4 